\title{
LETTER
}

\section{Graphical analysis of rare gas mixing systematics in geothermal systems}

\author{
DAVID M. Pyle \\ Department of Earth Sciences, University of Cambridge, Downing Street, \\ Cambridge CB2 3EQ, UK
}

(Received May 1, 1992; Accepted April 8, 1993)

\begin{abstract}
The utility of helium and neon isotopes as tracers of mixing in geothermal systems may be enhanced by employing an appropriate method of graphical analysis. On linear ${ }^{3} \mathrm{He} /{ }^{4} \mathrm{He}-{ }^{20} \mathrm{Ne} /{ }^{4} \mathrm{He}$ diagrams mixing is revealed by straight lines. This is contrary to the current procedure of plotting ${ }^{3} \mathrm{He} /{ }^{4} \mathrm{He}$ against ${ }^{4} \mathrm{He} /{ }^{20} \mathrm{Ne}$, where mixing lines are curved. Construction of triangular mixing plots with such data allows an immediate quantitative assessment of the extent to which the measured isotopic ratios reflect those of different endmembers (e.g. atmospheric, radiogenic and magmatic) and allows one to use these plots to compare the sources of rare gases in geothermal systems from different parts of the globe.
\end{abstract}

\section{INTRODUCTION}

The rare gases can be used as geochemical tracers of the interaction of different portions of the earth. Their use as indices of deep-seated heat production and magmatism are well established (e.g. Lupton, 1983; O'Nions and Oxburgh, 1983). Helium and neon isotope data have been reported from a number of geothermal systems. In such systems $\mathrm{He}$ and $\mathrm{Ne}$ are believed to originate from one of three sources: the atmosphere, deep-seated degassing of magma and radiogenic production in the host rocks and fluids. ${ }^{3} \mathrm{He}$ is primarily a tracer of the magmatic component (Clarke et al., 1969; Tolstikhin, 1978), while ${ }^{20} \mathrm{Ne}$ is a tracer of the atmospheric component (Craig et al., 1978). Commonly, such data are plotted on ${ }^{3} \mathrm{He} /{ }^{4} \mathrm{He}-$ ${ }^{4} \mathrm{He} /{ }^{20} \mathrm{Ne}$ diagrams (e.g. Lupton et al., 1977; Nagao et al., 1979; Torgersen and Jenkins, 1982; Sano and Wakita, 1985). These diagrams effectively plot $1 /{ }^{4} \mathrm{He}$ against ${ }^{4} \mathrm{He}$. Hence, mixing lines between any two points on these diagrams are curved. This problem is not solved when using logarithmic scales. Logarithmic ${ }^{3} \mathrm{He} /{ }^{4} \mathrm{He}-$
${ }^{4} \mathrm{He} /{ }^{20} \mathrm{Ne}$ and ${ }^{3} \mathrm{He} /{ }^{4} \mathrm{He}-{ }^{20} \mathrm{Ne} /{ }^{4} \mathrm{He}$ diagrams have both been used (e.g. Sano and Wakita, 1986); these are essentially mirror-images of each other $(\log (x)=-\log (1 / x))$, and while each can be used to plot ratios varying over orders of magnitude, trends are invariably curved. Similar problems are encountered when plotting ${ }^{3} \mathrm{He} /{ }^{4} \mathrm{He}$ against ${ }^{3} \mathrm{He} /{ }^{20} \mathrm{Ne}$ (e.g. Lupton, 1983); this effectively plots $1 / x$ against $1 / y$. For illustrative purposes one such diagram is shown in Fig. 1 (after Sano and Wakita, 1985). Such curved plots are difficult to understand, and do not assist in quantitatively constraining the mixing characteristics of the system. Since the ${ }^{4} \mathrm{He} /{ }^{20} \mathrm{Ne}$ ratios of the "magmatic" and "radiogenic" endmembers are not known precisely at any one location, but are constrained to be high $\left(>10-10^{4}\right.$ in the case of back-arc basin and ocean-ridge basalts: Lupton and Craig, 1975; Craig and Lupton, 1976), there is the additional problem that endmember compositions do not plot at a single point on such a plot.

Here it is proposed that data should be plotted on linear ${ }^{3} \mathrm{He} /{ }^{4} \mathrm{He}-{ }^{20} \mathrm{Ne} /{ }^{4} \mathrm{He}$ diagrams (Fig. 2a-d). This has a number of virtues: 


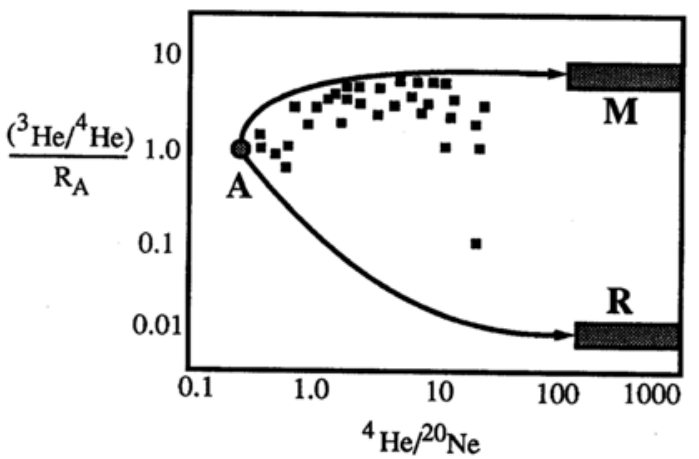

Fig. 1. Conventional ${ }^{3} \mathrm{He} /{ }^{4} \mathrm{He}-{ }^{4} \mathrm{He} /{ }^{20} \mathrm{Ne}$ plot for data from geothermal systems, adapted from Sano and Wakita (1985). The helium data, from natural gases and waters, are normalised to the atmospheric ratio, $R_{A}$. Mixing lines between air $(A)$, magma $(M)$ and radiogenic helium $(R)$ on this plot are curved. While scatter of data suggests that three-component mixing is taking place, it is not possible to assess quantitatively the contribution of any endmember component to any sample. The interpretation problem is accentuated by the use of a logarithmic scale along both axes, giving the erroneous impression that few of the data are contaminated with a radiogenic component. Note that neither the magmatic nor radiogenic endmembers can be plotted as a single point, since the ${ }^{4} \mathrm{He} /{ }^{20} \mathrm{Ne}$ ratio of each is only known to be $>10^{2}$.

1. Mixing lines between any points on such plots are linear (Fig. 2a).

2. The magmatic and radiogenic endmembers can be plotted as single points, with ${ }^{20} \mathrm{Ne} /{ }^{4} \mathrm{He} \sim 0$ and $\left({ }^{3} \mathrm{He} /{ }^{4} \mathrm{He}\right) \mathrm{R}_{\mathrm{A}} \sim 0$ respectively.

3. The endmembers define the apices of a triangle and allow immediate visual assessment of the amount of mixing between different components. The exact amounts of mixing at any point can be read off the plot using the simple lever rule. This removes the necessity of solving sets of simultaneous mass balance equations to evaluate the degree of interaction of endmember components (e.g. Sano and Wakita, 1985). This triangle is exactly analogous to the $\mathrm{CO}_{2}-\mathrm{N}_{2}-\mathrm{Ar}$ (and other) ternary plots used in the analysis of chemical compositions of fumarolic discharges elsewhere (e.g. Giggenbach, 1987).

In the following sections four representative examples are presented to illustrate the use of this tool.

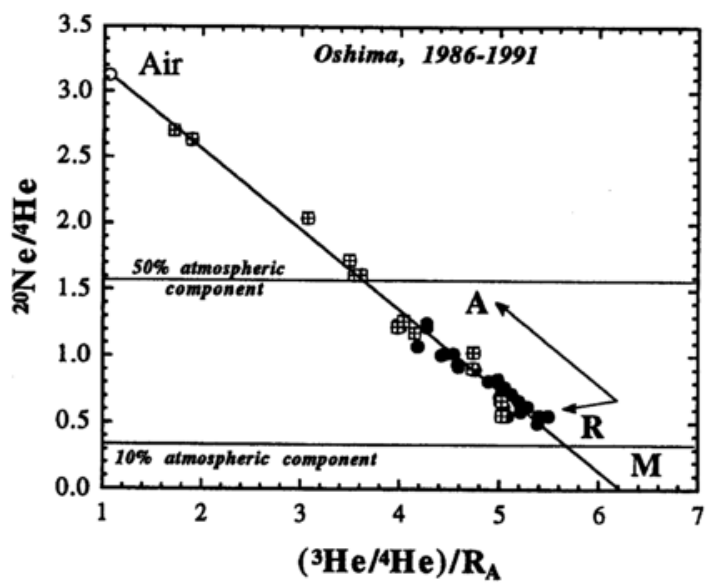

Fig. 2a. High-temperature gas data from Sano et al., $(1988,1991)$ are shown. These represent volcanic gas samples from Mt. Mihara, Oshima collected between 1986 and 1991 during a period of active volcanism. Data fall on a linear array, described by $\left\{{ }^{20} \mathrm{Ne} /{ }^{4} \mathrm{He}=3.765-0.6074 x\left({ }^{3} \mathrm{He} /{ }^{4} \mathrm{He}\right) / R_{A}\right\}$, with a correlation coefficient of 0.99. The two endmembers of the array are ambient air and magmatic helium with $\left.\beta \mathrm{He} /{ }^{4} \mathrm{He}\right) / R_{A}=6.20$, labelled $M$. Two arrows illustrating the effects of mixing are shown. The arrow labelled $R$ is the mixing trajectory for a sample with $\left.{ }^{20} \mathrm{Ne} /{ }^{4} \mathrm{He} \sim 0.6, \beta \mathrm{He} /{ }^{4} \mathrm{He}\right) / R_{A} \sim 6.2$ with a radiogenic helium source with ${ }^{20} \mathrm{Ne} /{ }^{4} \mathrm{He}<0.1$ and $3 \mathrm{He} /{ }^{4} \mathrm{He}$ ) $/ R_{A} \sim 10^{-2}$. Trajectory " $A$ " is for the same sample mixing with air.

\section{Oshima Volcano, Japan}

Data from Sano et al., $(1988,1991)$ are replotted in Fig. $2 \mathrm{a}$ on a ${ }^{20} \mathrm{Ne} /{ }^{4} \mathrm{He}-\left({ }^{4} \mathrm{He} /{ }^{3} \mathrm{He}\right) / \mathrm{R}_{\mathrm{A}}$ plot. $\mathbf{R}_{\mathrm{A}}$ is the atmospheric ${ }^{3} \mathrm{He} /{ }^{4} \mathrm{He}$ ratio $\left(\sim 1.4 \times 10^{-6}\right)$. The data define a well correlated linear array, with a correlation coefficient of 0.993 . This array reflects the mixing of two endmembers: air, with $\left({ }^{3} \mathrm{He} /{ }^{4} \mathrm{He}\right) \mathrm{R}_{\mathrm{A}}=1.0$ and ${ }^{20} \mathrm{Ne} /{ }^{4} \mathrm{He}=3.16$, and a "magmatic" component with ${ }^{20} \mathrm{Ne} /{ }^{4} \mathrm{He}=0,\left({ }^{3} \mathrm{He} /{ }^{4} \mathrm{He}\right) / \mathrm{R}_{\mathrm{A}}=6.20$. Up to $81 \%$ of the ${ }^{4} \mathrm{He}$ was derived from this magmatic component. Sano et al. (1988) assumed a magmatic $R / R_{A}$ of 8.0 , for which there is no evidence from these data alone. There was no significant contribution from radiogenic helium during this mixing, although the low $R / R_{A}$ value of the "magmatic" component suggests the involvement of radiogenic $\mathrm{He}$ during magmagenesis. 


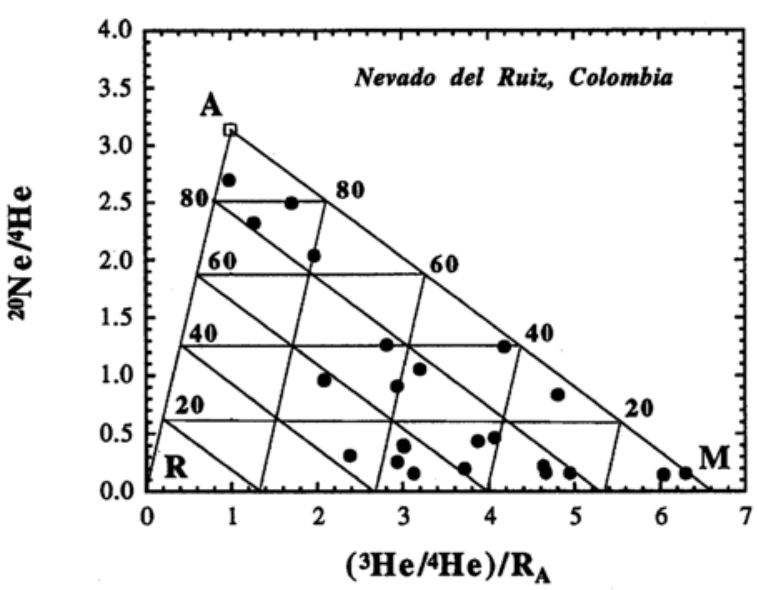

Fig. 2b. A typical triangular mixing plot for data from Japan. The three endmembers ( $A=$ atmospheric; $R=$ radiogenic; $M=$ magmatic) each define one apex of the triangle. The ${ }^{20} \mathrm{Ne} /{ }^{4} \mathrm{He}$ value of the atmospheric component (air) has been taken as 3.15. This is the ratio of $\mathrm{Ne}$ (18.18 ppmv) and $\mathrm{He}$ (5.24 ppmv, Weast 1988), corrected for the $90.9 \%$ natural abundance of ${ }^{20} \mathrm{Ne}$. The triangular plot is contoured in $20 \%$ intervals. To construct the plot, each side of the triangle (e.g. the line $R-M$ ) is divided into 5 equally sized segments, representing increments of mixing of $20 \%$ of He from R into $M$. The side $\mathrm{R}-M$ is the locus of compositions where $A=0$; lines parallel to $R-M$ contain $20 \%, 40 \% \cdots 100 \%$ of He from component $A$. The relative proportions of $A, R$ and $M$ in any composition which falls within the triangle can be read from the plot immediately. In this case, gases with up to $100 \%$ of each endmember can be recognised. Data sources: Nagao et al., 1979: gas samples; Sano and Wakita 1985: gas samples; Sano and Wakita 1988: gas samples; Marty et al., 1989: gas samples.

\section{Volcanic gases from Japan}

Data from Nagao et al., (1979), Sano and Wakita $(1985 ; 1988)$ and Marty et al., (1989) are replotted in Fig. 2b. All except two of the data fall within the mixing triangle, and can therefore be explained as simple mixtures of atmospheric (A), magmatic (M) and radiogenic (R) helium and neon. The majority of the samples analysed contain less than $10 \%$ atmospheric ${ }^{4} \mathrm{He}$. Sample compositions cover essentially the full range between the assumed magmatic and radiogenic endmembers.

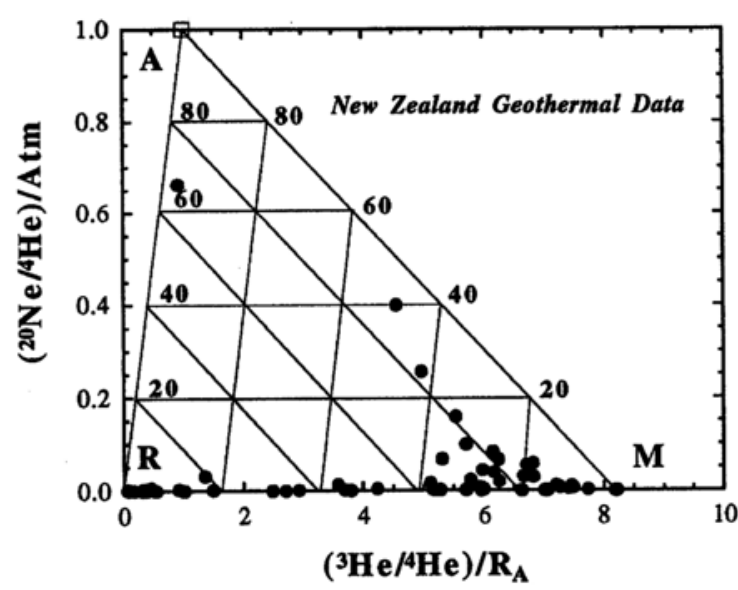

Fig. 2c. New Zealand geothermal data (Torgersen et al., 1982; Sano et al., 1987: gas samples) are replotted. Note that in this case, the plot is of ${ }^{20} \mathrm{Ne} /{ }^{4} \mathrm{He}$ normalized to the atmospheric ratio, so that the y scale runs from 0 to 1.0. The triangular mixing plot is the same as that for Fig. $2 b$.

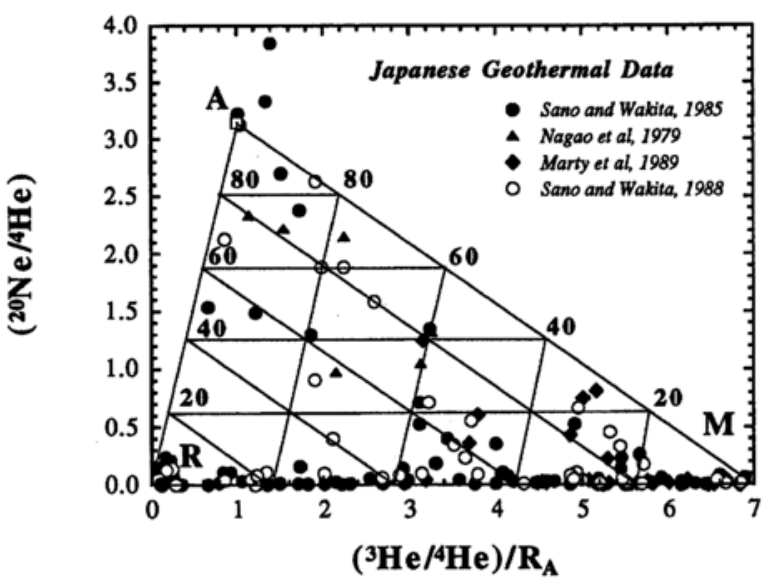

Fig. 2d. Data from samples collected soon after the eruption of Nevado del Ruiz, Colombia, and within $10 \mathrm{~km}$ of the crater (Williams et al., 1987: water and gas; Sano et al., 1990: water and gas samples). There is a smaller radiogenic component in these samples than in Figs. $2 b$ or $c$.

\section{New Zealand}

Data from Sano et al., (1987) and Torgersen et al., (1982) are replotted in Fig. 2c. In this example, the ${ }^{20} \mathrm{Ne} /{ }^{4} \mathrm{He}$ is normalised to the atmospheric ratio. Three components have been involved in mixing. The atmospheric component has contributed less than $20 \%$ of the helium in all except three cases. Significant dilution of the 
magmatic $\mathrm{He}$ with a radiogenic component is revealed. The magmatic endmember has ${ }^{3} \mathrm{He} /{ }^{4} \mathrm{He}$ of at least $8.2 \mathrm{R}_{\mathrm{A}}$.

\section{Nevado del Ruiz, Colombia}

Data from samples collected after the 1985 eruption of Nevado del Ruiz by Williams et al., (1987) and Sano et al., (1990) are replotted on Fig. 2d. In this example, the atmospheric component (A) ranges between $<5 \%$ and $85 \%$. There is significantly less dilution of the magmatic component with radiogenic helium $(<60 \%)$ than in the two previous examples (Figs. 2b, c).

\section{Discussion}

The utility of this method of plotting the data compared to conventional methods has been illustrated in the previous sections. In each case the magmatic endmember was chosen essentially arbitrarily, as the point with the highest $\left({ }^{3} \mathrm{He} /{ }^{4} \mathrm{He}\right) / \mathrm{R}_{\mathrm{A}}$ at ${ }^{20} \mathrm{Ne} /{ }^{4} \mathrm{He}=0$. The ${ }^{20} \mathrm{Ne} /{ }^{4} \mathrm{He}$ ratio of air (3.15; Weast 1988) was also adopted as the atmospheric reference point. Water in equilibrium with the atmosphere will have ${ }^{20} \mathrm{Ne} /{ }^{4} \mathrm{He} \sim 3.42$ at $10^{\circ} \mathrm{C}$ (Benson and Krause, 1976). With increasing temperature the ratio of the Bunsen (solubility) coefficients falls, so that the equilibrium ${ }^{20} \mathrm{Ne} /{ }^{4} \mathrm{He}$ ratio is $\sim 3.05$ at $50^{\circ} \mathrm{C}$, and $\sim 1.6$ at $150^{\circ} \mathrm{C}$ under pressure (Benson and Krause, 1976; Potter and Clynne, 1978). This reflects the enhanced solubility of Ne compared to $\mathrm{He}$ at low temperature, and the increasingly favoured solubility of $\mathrm{He}$ at higher temperatures. The exact value of the atmospheric ${ }^{20} \mathrm{Ne} /{ }^{4} \mathrm{He}$ ratio to adopt for non-gaseous samples is not clear (e.g. Craig et al., 1978; Marty et al., 1989). In any case, of all the data plotted (Fig. 2) only two samples (Fig. 2b) plot at points which cannot have mixed with air with ${ }^{20} \mathrm{Ne} /{ }^{4} \mathrm{He} \sim 3.15$ as an endmember.

A small atmospheric component may be introduced during sampling or by entrainment just prior to collection, in which case its presence may be regarded merely as a nuisance. Alternatively it may reflect deeper contact of fluids which had previously equilibrated with the at- mosphere, but which have not yet taken on a radiogenic signature. In this case the presence of an atmospheric component and the monitoring of its change with time may prove to be a useful tool for prediction of volcanic hazards. A prime example might be in a system where monitoring reveals the proximity of hot magma or magmatic fluids to near-surface waters (e.g. Sano et al., $1988,1991)$. In instances such as this, diagrams of the form proposed here should be employed. In other cases, where the amount of atmospheric contamination is small, and consequently ${ }^{20} \mathrm{Ne} /{ }^{4} \mathrm{He}$ ratios and variations might be expected to be small, one should examine a suitably expanded portion of the plot to obtain information on the primary magmatic or radiogenic components (e.g. Lupton and Craig 1975; Lupton et al., 1977). In any case, these measurements are merely a first step towards an improved understanding of the dynamics of geothermal systems. The data obtained from this plot yield information on the proportion of $\mathrm{He}$ or $\mathrm{Ne}$ atoms originating in one source or another. To understand the volumetric proportions of the endmember fluids rare gas concentration data are required.

\section{Conclusions}

The graphical analysis of data is of immense value for problem solving, but requires some thought in the design. Under some circumstances, conventional ${ }^{3} \mathrm{He} /{ }^{4} \mathrm{He}-{ }^{4} \mathrm{He} /{ }^{20} \mathrm{Ne}$ plots of rare gas isotopic data serve to obscure rather than illuminate mixing and other processes. Helium and neon isotopic data from geothermal systems, particularly those involving air-saturated fluids, should be plotted on linear ${ }^{3} \mathrm{He} /{ }^{4} \mathrm{He}-{ }^{20} \mathrm{Ne} /{ }^{4} \mathrm{He}$ diagrams. On this plot mixing lines between any points are linear. Magmatic and radiogenic endmembers can be plotted as points, rather than lines, with ${ }^{20} \mathrm{Ne} /{ }^{4} \mathrm{He} \sim 0$ and $\left({ }^{3} \mathrm{He} /{ }^{4} \mathrm{He}\right) / \mathbf{R}_{\mathrm{A}} \sim 0$ respectively. The endmembers define the apices of a triangle and allow immediate quantitative assessment of the amount of mixing between different components. 
Acknowledgments-I thank St. Catharine's College, Cambridge for a Research Fellowship, Chris Ballentine for discussion and Stan Williams and five others for reviews of earlier versions of the manuscript.

\section{REFERENCES}

Benson, B. B. and Krause, D. (1976) Empirical laws for dilute aqueous solutions of non-polar gases. $J$. Chem. Phys. 64, 689-674.

Clarke, W. B., Beg, M. A. and Craig, H. (1969) Excess ${ }^{3} \mathrm{He}$ in the sea: evidence for terrestrial primordial helium. Earth Planet. Sci. Lett. 6, 213-220.

Craig, H. and Lupton, J. E. (1976) Primordial neon, helium and hydrogen in oceanic basalts. Earth Planet. Sci. Lett. 31, 369-385.

Craig, H., Lupton, J. E. and Horibe, Y. (1978) A mantle helium component in circum-pacific volcanic gases: Hakone, the Marianas and Mt. Lassen. In Terrestrial Rare Gases (eds. E. C. Alexander and M. Ozima), Japan Sci. Soc. Press, Tokyo, 3-16.

Giggenbach, W. F. (1987) Redox processes governing the chemistry of fumarolic gas discharges from White Island, New Zealand. Appl. Geochem. 2, 143-161.

Lupton, J. E. (1983) Terrestrial inert gases: isotope tracer studies and clues to primordial components in the mantle. Ann. Rev. Earth Planet. Sci. 11, 371414.

Lupton, J. E. and Craig, H. (1975) Excess ${ }^{3} \mathrm{He}$ in oceanic basalts: evidence for terrestrial primordial helium. Earth Planet. Sci. Lett. 26, 133-139.

Lupton, J. E., Weiss, R. F. and Craig, H. (1977) Mantle helium in the Red Sea brines. Nature 266, 244246.

Marty, B., Jambon, A. and Sano, Y. (1989) Helium isotopes and $\mathrm{CO}_{2}$ in volcanic gases of Japan. Chem. Geol. 76, 25-40.

Nagao, K., Takaoka, N. and Matsubayashi, O. (1979) Isotopic anomalies of rare gases in the Nigorikawa geothermal area, Hokkaido, Japan. Earth Planet. Sci. Lett. 44, 82-90.

O'Nions, R. K. and Oxburgh, E. R. (1983) Heat and Helium in the Earth. Nature 306, 429-431.

Potter, R. W. and Clynne, M. A. (1978) The solubility of the noble gases $\mathrm{He}, \mathrm{Ne}, \mathrm{Ar}, \mathrm{Kr}$ and $\mathrm{Xe}$ in water up to the critical point. J. Solution Chem. 7, 837-
844.

Sano, Y. and Wakita, H. (1985) Geographical distribution of ${ }^{3} \mathrm{He} /{ }^{4} \mathrm{He}$ ratios in Japan: implications for arc tectonics and incipient magmatism. J. Geophys. Res 90, 8729-8741.

Sano, Y. and Wakita, H. (1986) ${ }^{3} \mathrm{He} /{ }^{4} \mathrm{He}$ ratios of pore gases in pore waters, sites 583 and 584. Init. Repts. D. S. D. P. 87, 861-864.

Sano, Y. and Wakita, H. (1988) Helium isotope ratio and heat discharge rate in the Hokkaido Island, Northeast Japan. Geochem. J. 22, 293-303.

Sano, Y., Wakita, H. and Giggenbach, W. (1987) Island arc tectonics of New Zealand manifested in helium isotope ratios. Geochim. Cosmochim. Acta 51, $1855-1860$.

Sano, Y., Nakamura, Y., Notsu, K. and Wakita, H. (1988) Influence of volcanic eruptions on helium isotope ratios in hydrothermal systems induced by volcanic eruptions. Geochim. Cosmochim. Acta 52, 1305-1308.

Sano, Y., Wakita, H. and Williams, S. N. (1990) Helium-isotope systematics at Nevado del Ruiz volcano, Colombia: implications for the volcanic hydrothermal system. J. Volcanol. Geotherm. Res 42, 41-52.

Sano, Y., Notsu, K., Ishibashi, J-I., Igarashi, G. and Wakita, H. (1991) Secular variations in helium isotope ratios in an active volcano: eruption and plug hypothesis. Earth Planet. Sci. Lett. 107, 95100.

Tolstikhin, I. N. (1978) A review: some advances in isotope geochemistry of light rare gases. In Terrestrial Rare Gases (eds. E. C. Alexander and M. Ozima), Japan Sci. Soc. Press, Tokyo, 33-62.

Torgersen, T. and Jenkins, W. J. (1982) Helium isotopes in geothermal systems: Iceland, The Geysers, Raft River and Steamboat Springs. Geochim. Cosmochim. Acta 46, 739-748.

Torgersen, T., Lupton, J. E., Sheppard, D. S. and Giggenbach, W. F. (1982) Helium isotope variations in the thermal areas of New Zealand. $J$. Volcanol. Geotherm. Res. 12, 283-298.

Weast, R. C. (ed) (1988) Handbook of Chemistry and Physics 68th edition, 1987-1988 CRC Press Inc., Roca Baton, Florida.

Williams, S. N., Sano, Y. and Wakita, H. (1987) Helium-3 emission from Nevado del Ruiz volcano, Colombia. Geophys. Res. Lett. 14, 1035-1038. 